\title{
The impact of first and second eye cataract surgeries on falls: a prospective cohort study
}

This article was published in the following Dove Press journal:

Clinical Interventions in Aging

\section{Ying Ru Feng ${ }^{1,2}$ \\ Lynn B Meuleners ${ }^{2}$ \\ Michelle L Fraser ${ }^{2}$ \\ Kate J Brameld ${ }^{2}$ \\ Seraina Agramunt ${ }^{2}$}

'School of Population and Global Health, Faculty of Health and Medical Sciences, The University of Western Australia, Perth, WA, Australia; ${ }^{2}$ Curtin-Monash Accident Research Centre (C-MARC), Faculty of Health Sciences, Curtin University, Perth, WA, Australia
Correspondence: Lynn B Meuleners Curtin-Monash Accident Research Centre (C-MARC), Faculty of Health Sciences, Curtin University, GPO Box UI987, Perth, WA 6845, Australia

$\mathrm{Tel}+6 I 892664636$

Fax +6189266 I6II

Email l.meuleners@curtin.edu.au
Purpose: The purpose of this study was to investigate the impact of the first and second eye cataract surgeries on the risk of falls in participants with bilateral cataract and to determine which changes in visual measures are associated with changes in the number of falls throughout the cataract surgery process.

Patients and methods: Fifty-five older adults with bilateral cataract aged 55+ years were assessed at three time points during the cataract surgery process, and they completed a falls diary. Two separate generalized estimating equation-negative binomial models were undertaken to assess changes in the number of falls before first eye cataract surgery, between first and second eye surgeries, and after second eye cataract surgery and which changes in visual measures were associated with changes in the number of falls.

Results: After adjusting for potential confounding factors, the risk of falls decreased by $54 \%$ (incidence rate ratio $(\mathrm{IRR})=0.458,95 \% \mathrm{CI}=0.215-0.974, p=0.04$ ) after first eye cataract surgery only, compared with the period before first eye surgery. The risk of falls decreased by $73 \%($ IRR $=0.268,95 \% \mathrm{CI}=0.114-0.628, p=0.002)$ after second eye cataract surgery, compared with the period before first eye surgery. Improved binocular visual acuity (IRR $=5.488$, $95 \% \mathrm{CI}=1.191-25.282, p=0.029)$ and contrast sensitivity $(\mathrm{IRR}=0.257,95 \% \mathrm{CI}=0.070-0.939$, $p=0.040$ ) were associated with a decrease in the number of falls.

Conclusion: The study found that first and second eye cataract surgeries reduced the risk of falls among a cohort of bilateral cataract patients with relatively good baseline vision. This suggests that timely first and second eye cataract surgeries could play an important role in reducing the burden due to falls among older adults with cataract.

Keywords: vision, bilateral cataract, older population, injuries

\section{Introduction}

Vision is an important factor in the risk of falls, estimated to account for a quarter to half of all falls in older adults. ${ }^{1}$ One of the most common causes of visual impairment in older people is cataract. ${ }^{2,3}$ Although most people by the age of 70 years will have developed cataract, it is effectively treated by cataract surgery which is the most commonly performed ophthalmic procedure worldwide. ${ }^{4}$ The number of cataract surgeries performed in Australia increased by more than threefold in the past two decades, largely due to the aging population. ${ }^{2}$

Cataract surgery has the potential to correct impaired vision and, hence, may impact on the risk of falls. While an earlier meta-analysis found that evidence was inconclusive on the effectiveness of expedited cataract surgery in reducing falls, ${ }^{5}$ more recent studies have reported significant reductions in falls following first eye cataract surgery of $33 \%{ }^{6}$ and $78 \%{ }^{7}$ In contrast, a population-based study in Western Australia found that the risk of serious falls requiring hospitalization doubled after first eye 
cataract surgery, then reduced after second eye surgery, but the risk still remained higher than before first eye surgery. ${ }^{8}$ Therefore, little is known about the specific impact of second eye cataract surgery on less serious falls which do not require hospitalization.

Cataract surgery is performed on each eye separately, with a variable waiting period between first and second eye surgeries. However, only first eye surgery can result in significant differences in vision between the operated and un-operated eyes, and previous studies have illustrated the additional visual benefits of second eye cataract surgery. ${ }^{4,9-12}$ It is therefore essential to understand the separate impacts of first and second eye cataract surgeries on the risk of falls for bilateral cataract patients.

To date, there are also inconsistent findings on the association between measures of vision and falls risk among cataract patients. The three most common visual measures are visual acuity (sharpness of vision), contrast sensitivity (the ability to detect contrast in luminance), and stereopsis (a form of depth perception). Studies investigating the association between the visual measures and falls have demonstrated that poorer visual acuity is often associated with a higher risk of falls. ${ }^{13,14}$ However, there is a limited evidence on the effect of contrast sensitivity and stereopsis on the risk of falling, despite their important roles in situations of low light and for negotiating stairs. For cataract studies specifically, one report indicated that improved contrast sensitivity was the only visual measure significantly associated with a decrease in falls after surgery ${ }^{7}$ while another reported that visual acuity was the only measure associated with falls. ${ }^{6}$ It is important to clarify the role of specific visual measures in falls risk for cataract patients so they can be advised by clinicians and possibly prioritized for surgery.

The aim of this study was to investigate the impact of first and second eye cataract surgeries on the risk of a fall for participants with bilateral cataract. The secondary aim was to determine which changes in visual measures are associated with changes in the number of falls throughout the cataract surgery process.

\section{Patients and methods Study design}

A prospective longitudinal cohort study was undertaken among participants with bilateral cataract who were awaiting first eye cataract surgery in Perth, Western Australia.

\section{Participants}

Participants were consecutively recruited from three public hospital eye clinics in Western Australia through a letter of invitation, followed up with a call by the researcher or they were directly approached by an ophthalmologist from the hospital. Inclusion criteria stipulated that participants were aged over 55 years, had no other significant eye conditions (eg, glaucoma, macular degeneration, diabetic retinopathy) and a Mini Mental State Examination (MMSE) ${ }^{15}$ score $\geq 24$, indicating normal cognitive function. Exclusion criteria were being wheel-chair bound, diagnosed with dementia, Alzheimer's disease, Parkinson's disease, non-English speaking, living in a residential facility or had undergone previous cataract surgery. All cataract surgeries were undertaken by phacoemulsification and performed one eye at a time.

The sample size was adequate to detect changes in falls throughout the cataract surgery process. Assuming that $25 \%$ of cataract patients will experience at least one fall (of any severity) before first eye cataract surgery, ${ }^{15}$ a sample size of 55 participants would be able to detect a $70 \%$ reduction in falls after first and second eye cataract surgeries with a power of $80 \%$ at a $5 \%$ significance level.

\section{Data collection}

Recruitment of participants occurred between December 2014 and February 2017. Data collection involved a falls diary, a researcher-administered questionnaire, the MMSE, ${ }^{16}$ and three objective visual assessments. The data collection interviews occurred at three time points: in the month before first eye cataract surgery (baseline), between first and second eye cataract surgeries (first follow-up) and at least 1 month after second eye cataract surgery (second follow-up). All assessments were undertaken at Curtin University. Participants were followed up further for a 4-6 months after the second follow-up assessment in order to collect additional information about whether they had a fall during this time. Informed written consent was obtained prior to the collection of information from participants, following the tenets of the Declaration of Helsinki. Ethics approval was obtained from the hospitals involved and the Curtin University Human Research Ethics Committee.

\section{Falls diary}

A fall was defined as "an unexpected event in which the participant comes to rest on the ground, floor or lower level." ${ }^{17}$ Participants were provided with a falls diary at the baseline assessment that was returned to the researcher by the participant every month throughout the study period. For each fall, the date, time, place, activity, circumstance, and severity of the fall were recorded by the participants in the diary. A follow-up call to each participant was made at the end of each month after the baseline assessment by the 
researcher to confirm whether a fall was recorded in the diary or not.

\section{Questionnaires}

Sociodemographic data

Information including age, gender, marital status, country of birth, education level, living arrangements, self-reported medications, and comorbidities were obtained through a researcher-administered questionnaire.

\section{Physical activity}

Physical activity levels were assessed at each data collection point by using items from the Active Australia Survey. ${ }^{18}$ Questions on physical activity included the number of times the following activities were completed in the last week and the total time spent doing these activities: walking continuously, vigorous gardening/heavy work around the yard, vigorous physical activities, and moderate physical activities. Recommended "sufficient" physical activity is described as: 1) 30 minutes of activity on at least 5 days of the week or 2) a total of at least 150 minutes of activity per week. ${ }^{18}$ Sufficient activity was included in the model to account for changes in physical activity during the cataract surgery process.

\section{Cognitive assessment}

The $\mathrm{MMSE}^{16}$ was used to assess general cognitive function and screen for cognitive impairment. Scores from this examination range from 0 to 30 with a score of $\geq 24$ indicating normal cognitive function.

\section{Measures of vision}

Three objective visual measurements were obtained under the guidance of an ophthalmologist under standard conditions, constant luminance, and without mydriasis. Participants wore their habitual corrective wear for testing (near correction for contrast sensitivity and stereopsis tests and distance correction for the visual acuity test).

Monocular and binocular visual acuity were assessed by an Early Treatment Diabetic Retinopathy Study acuity chart, calibrated for a distance of $3 \mathrm{~m} .{ }^{19}$ A letter-by-letter scoring method was used, and the scores were expressed as a logarithm of the minimum angle of resolution (logMAR). A lower logMAR score represents better vision. Monocular and binocular contrast sensitivity was assessed by the Mars Letter Contrast Sensitivity Test (Mars Perceptrix(C), at a distance of $50 \mathrm{~cm}$. The score was expressed as $\log$ units. A higher log unit score represents better vision. Stereopsis was assessed by the Titmus Fly Stereotest (Good-Lite Co., Inc,
Elgin, IL, USA). The score was expressed as log seconds of arc with lower scores representing better vision.

\section{Statistical analysis}

The primary outcome of interest was the total number of falls throughout the cataract surgery process. Descriptive and inferential statistics for those who did and did not experience a fall were initially undertaken to summarize the sociodemographic information and information on falls and physical activity throughout the cataract surgery process. Repeated measures of analysis of variance were used to assess changes in vision before first eye surgery, between first and second eye surgeries and after second eye surgery.

Two separate generalized estimating equation (GEE)negative binomial regression models were undertaken. The first GEE-negative binomial regression model analyzed whether there was a significant change in the number of falls after first and second eye cataract surgeries, while controlling for potential confounding factors. The visual measures were not included in this model because vision changed as a result of the surgery. The second model was undertaken to examine the changes in the three visual measures (visual acuity, contrast sensitivity, and stereopsis) and which were associated with changes in the number of falls.

The GEE-negative binomial regression models take account of the overdispersion of the outcome of interest (the number of falls) as well as the time periods before, between, and after the cataract surgeries. Three exposure periods were calculated - before first eye cataract surgery, the time between first and second eye cataract surgeries, and the time after second eye cataract surgery until the end of the diary follow-up using the logarithm of the time of the observation within each exposure period. The GEE method is suitable for longitudinal or repeated measures study designs where observations within each participant are not independent. ${ }^{20}$ GEEs permit specification of a certain working correlation matrix that accounts for this within-subject correlation, thus providing more robust regression coefficients.

Potential confounding factors included in both the models were: gender (female/male), age (55-64, 65-74, 75-84, $85+$ years), marital status (single/married or de facto), living arrangements (lives alone, not alone), medication usage (yes, no), and sufficient physical activity (yes, no). The presence of a comorbid condition was not included in the models since over $97 \%$ of participants had a comorbid condition. Refractive management was also not included since all visual tests were undertaken with the standard refractive management used by each participant in their daily lives. Analyses were undertaken using SAS software (v9.4; SAS Institute 
Inc., Cary, NC, USA), and $p$-values $<0.05$ were considered to be statistically significant.

\section{Results}

\section{Sample demographics}

A total of 55 participants completed all three assessments, resulting in a total of 165 observations. The average wait time between first and second eye cataract surgeries was 99.6 days ( $\mathrm{SD}=73.7$ ) with a range of 9-417 days. Following second eye surgery, participants were followed up for an average of 283 days $(\mathrm{SD}=52.2)$ with a range of $135-420$ days.

The sociodemographic characteristics of participants at baseline, after first and second eye cataract surgeries are presented by falls status for each period, in Table 1.

The mean age of the participants at baseline was 73.3 years $(\mathrm{SD}=7.7)$, ranging from 56.1 to 87.8 years. The majority of the participants were female $(n=30,54.6 \%)$, married or de facto $(n=34,61.8 \%)$, were not born in Australia $(n=34$, $61.8 \%)$, did not live alone $(n=30,54.6 \%)$, had higher than primary or secondary education $(n=32,58.2 \%)$, were on prescription medication $(n=48,87.3 \%)$, had at least one comorbid medical condition $(n=54,98.2 \%)$, and participated in "sufficient" physical activity at baseline ( $\mathrm{n}=31,56.4 \%)$. Status of prescription medication usage, comorbid medical conditions, and participation in "sufficient" physical activity changed during follow-up. At the first follow-up, the number of participants who were on prescription medication decreased to $46(83.6 \%)$, however, by the second follow-up this number had increased back up to 48 (87.3\%). At both first and second follow-ups, the number of participants who presented with comorbidities increased to 55 (100\%). The number of participants who participated in "sufficient"

Table I Participant characteristics by falls status before first eye cataract surgery, between first and second eye cataract surgeries, and after second eye cataract surgery $(n=55)$

\begin{tabular}{|c|c|c|c|c|c|c|c|c|c|c|c|c|}
\hline \multirow[t]{3}{*}{ Variables } & \multicolumn{4}{|c|}{ Baseline } & \multicolumn{4}{|c|}{ After first eye surgery } & \multicolumn{4}{|c|}{ After second eye surgery } \\
\hline & \multicolumn{2}{|c|}{$\begin{array}{l}\text { Fall }^{a} \\
(n=\mid 4)\end{array}$} & \multicolumn{2}{|c|}{$\begin{array}{l}\text { No fall } \\
(n=4 I)\end{array}$} & \multicolumn{2}{|c|}{$\begin{array}{l}\text { Fall } \\
(n=5)\end{array}$} & \multicolumn{2}{|c|}{$\begin{array}{l}\text { No fall } \\
(n=50)\end{array}$} & \multicolumn{2}{|c|}{$\begin{array}{l}\text { Fall } \\
(n=5)\end{array}$} & \multicolumn{2}{|c|}{$\begin{array}{l}\text { No fall } \\
(n=50)\end{array}$} \\
\hline & $\mathbf{n}$ & $\%$ & $\mathbf{n}$ & $\%$ & $\mathbf{n}$ & $\%$ & $\mathbf{n}$ & $\%$ & $\mathbf{n}$ & $\%$ & $\mathbf{n}$ & $\%$ \\
\hline \multicolumn{13}{|l|}{ Gender $^{\mathrm{b}}$} \\
\hline Female & 8 & 57.1 & 22 & 53.7 & 5 & 100 & 25 & 50 & 3 & 60 & 27 & 54 \\
\hline Male & 6 & 42.9 & 19 & 46.3 & 0 & 0 & 25 & 50 & 2 & 40 & 23 & 46 \\
\hline \multicolumn{13}{|l|}{ Age group (years) ${ }^{\mathrm{b}}$} \\
\hline $55-64$ & 3 & 21.4 & 7 & I7.I & 2 & 40 & 8 & 16 & 0 & 0 & 10 & 20 \\
\hline $65-74$ & 5 & 35.7 & 16 & 39 & 3 & 60 & 18 & 36 & 2 & 40 & 19 & 38 \\
\hline $75-84$ & 4 & 28.6 & 17 & 41.5 & 0 & 0 & 21 & 42 & 3 & 60 & 18 & 36 \\
\hline $85+$ & 2 & 14.3 & I & 2.4 & 0 & 0 & 3 & 6 & 0 & 0 & 3 & 6 \\
\hline \multicolumn{13}{|l|}{ Marital status ${ }^{b}$} \\
\hline Single, separated, divorced, widowed & 6 & 42.9 & 15 & 36.6 & 4 & 80 & 17 & 34 & I & 20 & 20 & 40 \\
\hline Married/de facto & 8 & 57.1 & 26 & 63.4 & I & 20 & 33 & 66 & 4 & 80 & 30 & 60 \\
\hline \multicolumn{13}{|l|}{ Living arrangements ${ }^{\mathrm{b}}$} \\
\hline Alone & 6 & 42.9 & 19 & 46.3 & 3 & 60 & 22 & 44 & 1 & 20 & 24 & 48 \\
\hline Not alone & 8 & 57.1 & 22 & 53.7 & 2 & 40 & 28 & 56 & 4 & 80 & 26 & 52 \\
\hline \multicolumn{13}{|l|}{ Education } \\
\hline Primary or secondary school & 7 & 50 & 16 & 39 & 2 & 40 & 21 & 42 & 4 & 80 & 19 & 38 \\
\hline Higher education & 7 & 50 & 25 & 61 & 3 & 60 & 29 & 58 & I & 20 & 31 & 62 \\
\hline \multicolumn{13}{|l|}{ Prescription medication ${ }^{\mathrm{b}}$} \\
\hline No & 4 & 28.6 & 3 & 7.3 & I & 20 & 8 & 16 & 2 & 40 & 5 & 10 \\
\hline Yes & 10 & 71.4 & 38 & 92.7 & 4 & 80 & 42 & 84 & 3 & 60 & 45 & 90 \\
\hline \multicolumn{13}{|l|}{ Comorbid conditions } \\
\hline No & 0 & 0 & I & 2.4 & 0 & 0 & 0 & 0 & 0 & 0 & 0 & 0 \\
\hline Yes & 14 & 100 & 40 & 97.6 & 5 & 100 & 50 & 100 & 5 & 100 & 50 & 100 \\
\hline \multicolumn{13}{|l|}{ Country of birth } \\
\hline Not Australia & 8 & 57.1 & 26 & 63.4 & 3 & 60 & 31 & 62 & 2 & 40 & 32 & 64 \\
\hline Australia & 6 & 42.9 & 15 & 36.6 & 2 & 40 & 19 & 38 & 3 & 60 & 18 & 36 \\
\hline \multicolumn{13}{|l|}{ Sufficient physical activity } \\
\hline No & 7 & 50 & 17 & 41.5 & I & 20 & 26 & 52 & 3 & 60 & 21 & 42 \\
\hline Yes & 7 & 50 & 24 & 58.5 & 4 & 80 & 24 & 48 & 2 & 40 & 29 & 58 \\
\hline
\end{tabular}

Notes: andividual level and not total number of falls; ' $V$ ariables adjusted in the GEE models in Tables 3 and 4.

Abbreviation: GEE, generalized estimating equation. 
physical activity decreased to $28(50.9 \%)$ at the first follow-up but increased back up to 31 (56.4\%) at the second follow-up (Table 1).

\section{Visual measures}

Visual measures at baseline and at the first and second follow-up assessments are presented in Table 2 .

Mean binocular visual acuity improved from 0.15 $\log$ MAR $(\mathrm{SD}=0.15)$ at baseline to $0.08 \log$ MAR $(\mathrm{SD}=0.21)$ after first eye surgery, and then further improved to -0.02 $\operatorname{logMAR}(\mathrm{SD}=0.19)$ after second eye surgery. This equates to 20/12.5 vision on a Snellen chart, which is better than 20/20 vision. Binocular contrast sensitivity increased (improved) from $1.64 \log$ units ( $\mathrm{SD}=0.14$ ) at baseline to $1.67 \log$ units $(\mathrm{SD}=0.21)$ after first eye surgery, and then further increased to $1.75 \log$ units $(\mathrm{SD}=0.08$ ) after second eye surgery. Stereopsis increased (improved) from $2.14 \mathrm{log}$ seconds of arc $(\mathrm{SD}=0.64)$ at baseline to $2.31 \log$ seconds of $\operatorname{arc}(\mathrm{SD}=0.72)$ after first eye surgery, and then further increased to 1.96 $\log$ seconds of arc ( $\mathrm{SD}=0.60)$ after second eye surgery. All changes in visual measures were significant $(p<0.05)$.

\section{Prevalence, severity, and location of falls}

Fourteen (25.5\%) of 55 participants had a total of 24 falls while waiting for first eye cataract surgery (Table 1). Of these participants, nine experienced one fall, four had three falls and one experienced four falls. Between first and second eye surgeries, five out of the 55 participants (9.1\%) experienced a total of nine falls with three participants falling once and three falling twice. After second eye surgery, five

Table 2 Visual function measurements before first eye cataract surgery, between first and second eye cataract surgeries, and after second eye cataract surgery

\begin{tabular}{|c|c|c|c|c|}
\hline & $\begin{array}{l}\text { Before } \\
\text { surgery } \\
\text { Mean (SD) } \\
\end{array}$ & $\begin{array}{l}\text { After first } \\
\text { eye surgery } \\
\text { Mean (SD) }\end{array}$ & $\begin{array}{l}\text { After second } \\
\text { eye surgery } \\
\text { Mean (SD) }\end{array}$ & $p$-values \\
\hline \multicolumn{5}{|c|}{ Visual acuity (logMAR)a } \\
\hline Better eye & $0.18(0.15)$ & $0.10(0.22)$ & $-0.00(0.19)$ & $<0.001 *$ \\
\hline Worse eye & $0.39(0.24)$ & $0.36(0.26)$ & $0.11(0.19)$ & $<0.00 I^{*}$ \\
\hline Binocular & $0.15(0.15)$ & $0.08(0.21)$ & $-0.02(0.19)$ & $<0.00 I^{*}$ \\
\hline \multicolumn{5}{|c|}{ Contrast sensitivity (log units) ${ }^{b}$} \\
\hline Better eye & $1.57(0.14)$ & $1.62(0.28)$ & $\mathrm{I} .68(0 . \mathrm{II})$ & $<0.00 I^{*}$ \\
\hline Worse eye & I.4I (0.29) & $\mathrm{I} .47(0.27)$ & $1.6 I(0.13)$ & $<0.001 *$ \\
\hline Binocular & $1.64(0.14)$ & $1.67(0.25)$ & $1.75(0.08)$ & $<0.001 *$ \\
\hline \multicolumn{5}{|c|}{ Stereopsis (log seconds of arc) ${ }^{c}$} \\
\hline Binocular & $2.14(0.64)$ & $2.31(0.72)$ & $1.96(0.60)$ & $0.002 *$ \\
\hline
\end{tabular}

Notes: ${ }^{\mathrm{a}, \mathrm{c} L}$ Lower scores represent better vision; ${ }^{\circ}$ Higher scores represent better vision; *Significant at $p<0.05$.

Abbreviations: log, logarithm; logMAR, logarithm of the minimal angle of resolution. out of 55 participants $(9.1 \%)$ experienced a total of seven falls, with three participants falling once and two falling twice (Table 1). Overall, nine of the 20 participants who fell during the entire study period experienced more than one fall. Only one participant experienced at least one fall in all three time periods and two participants fell in two different time periods. The remaining participants experienced falls in one time period only.

Overall, the majority of falls were minor with only five falls resulting in a visit to the general practitioner and no falls resulting in a hospitalization during the study period. All these falls occurred before the participant had first eye cataract surgery. The majority of falls occurred at home $(\mathrm{n}=22)$ with 10 of these occurring in the garden.

\section{Changes in falls over cataract surgery process}

The results of the GEE-negative binomial model examining change in falls before, between, and after cataract surgery are presented in Table 3. After adjusting for potential confounding factors, the risk of a fall decreased by $54 \%$ (incidence rate ratio $[\mathrm{IRR}]=0.458,95 \% \mathrm{CI}=0.215-0.974, p=0.043$ ) after

Table 3 GEE-negative binomial model of the impact of first and second eye cataract surgeries on the number of falls for older adults with bilateral cataract

\begin{tabular}{|c|c|c|c|}
\hline & IRR & $95 \% \mathrm{Cl}$ & p-values \\
\hline \multicolumn{4}{|l|}{ Cataract surgery } \\
\hline Before first eye surgery & I & & \\
\hline After first eye surgery & 0.458 & $0.215-0.974$ & $0.043^{*}$ \\
\hline After second eye surgery & 0.268 & $0.114-0.628$ & $0.002^{*}$ \\
\hline \multicolumn{4}{|l|}{ Gender } \\
\hline Female & I & & \\
\hline Male & 0.728 & $0.303-1.749$ & 0.479 \\
\hline \multicolumn{4}{|l|}{ Age group (years) } \\
\hline $55-64$ & I & & \\
\hline $65-74$ & 1.086 & $0.38 I-3.090$ & 0.876 \\
\hline $75-84$ & 0.757 & $0.256-2.222$ & 0.614 \\
\hline $85+$ & 1.898 & $0.414-8.697$ & 0.409 \\
\hline \multicolumn{4}{|l|}{ Marital status } \\
\hline Single & I & & \\
\hline Married/de facto & 0.346 & $0.142-0.845$ & $0.020^{*}$ \\
\hline \multicolumn{4}{|l|}{ Living arrangements } \\
\hline Lives with someone else & I & & \\
\hline Lives alone & 2.259 & $0.957-5.329$ & 0.063 \\
\hline \multicolumn{4}{|c|}{ Sufficient physical activity } \\
\hline Yes & 1 & & \\
\hline No & 0.955 & $0.453-2.014$ & 0.905 \\
\hline \multicolumn{4}{|l|}{ Prescribed medications } \\
\hline Yes & I & & \\
\hline No & 0.614 & $0.229-1.648$ & 0.334 \\
\hline
\end{tabular}

Note: *Significant at $p<0.05$.

Abbreviations: GEE, generalized estimating equation; IRR, incidence rate ratio. 
Table 4 GEE-negative binomial regression model of changes in visual measures and the number of falls before, between and after first and second eye cataract surgeries among older adults with bilateral cataract

\begin{tabular}{|c|c|c|c|}
\hline & IRR & $95 \% \mathrm{Cl}$ & $p$-values \\
\hline Binocular contrast sensitivity & 0.257 & $0.070-0.939$ & $0.040 *$ \\
\hline Binocular visual acuity & 5.488 & I.19I-25.282 & $0.029 *$ \\
\hline Stereopsis & 1.489 & $0.852-2.516$ & 0.163 \\
\hline \multicolumn{4}{|l|}{ Gender } \\
\hline Female & I & & \\
\hline Male & 0.690 & $0.297-1.604$ & 0.390 \\
\hline \multicolumn{4}{|l|}{ Age group (years) } \\
\hline $55-64$ & 1 & & \\
\hline $65-74$ & 0.1 & $0.0-0.7$ & 0.11 \\
\hline $75-84$ & 0.7 & $0.1-5.3$ & 0.75 \\
\hline $85+$ & 0.8 & $0.0-28.1$ & 0.90 \\
\hline \multicolumn{4}{|l|}{ Marital status } \\
\hline Single & I & & \\
\hline Married/de facto & 0.503 & $0.212-1.196$ & 0.120 \\
\hline \multicolumn{4}{|l|}{ Living arrangements } \\
\hline Lives with someone else & I & & \\
\hline Lives alone & 2.236 & $1.04-4.764$ & $0.037 *$ \\
\hline \multicolumn{4}{|l|}{ Sufficient physical activity } \\
\hline Yes & I & & \\
\hline No & $0.88 \mathrm{I}$ & $0.418-1.858$ & $0.74 I$ \\
\hline \multicolumn{4}{|l|}{ Prescribed medications } \\
\hline Yes & 1 & & \\
\hline No & 0.439 & $0.167-1.153$ & 0.095 \\
\hline
\end{tabular}

Note: *Significant at $p<0.05$.

Abbreviations: GEE, generalized estimating equation; IRR, incidence rate ratio.

the first eye cataract surgery only, compared to the period before first eye surgery. The risk of a fall decreased by $73 \%$ (IRR $=0.268,95 \% \mathrm{CI}=0.114-0.628, p=0.002)$ after second eye cataract surgery, compared to the period before first eye surgery. Those who were married or in a de facto relationship also had a significantly decreased risk of falls by $65 \%$ ( $\mathrm{IRR}=0.346,95 \% \mathrm{CI}=0.142-0.845, p=0.020$ ).

The results of the GEE-negative binomial model examining changes in visual measures and the number of falls are presented in Table 4. Binocular contrast sensitivity was significantly associated with the change in falls. For every one log unit increase in contrast sensitivity score (improved contrast sensitivity), the number of falls decreased by $74 \%$ (IRR $=0.257,95 \%$ CI $=0.070-0.939, p=0.040$ ). Binocular visual acuity was also significantly associated with the change in falls, with higher scores (worse visual acuity) associated with an increased number of falls (IRR $=5.488$, $95 \% \mathrm{CI}=1.191-25.282, p=0.029$ ).

\section{Discussion}

This study found that first eye cataract surgery resulted in a $54 \%$ reduction in the number of falls and second eye surgery provided additional benefits ( $73 \%$ reduction), compared to before the first eye surgery. In addition, changes in visual acuity and contrast sensitivity were associated with the decrease in falls over the cataract surgery process.

The findings are consistent with those of a Vietnamese study that reported a $78 \%$ decrease in falls for participants who underwent first eye cataract surgery only and an $83 \%$ decrease for those who underwent both first and second eye surgeries. ${ }^{7}$ However, earlier randomized controlled trials reported that while first eye cataract surgery reduced falls risk, ${ }^{21}$ second eye surgery had no effect on falls for women aged over 70 years. ${ }^{22}$ Reason for these conflicting findings for second eye surgery could be the older age of the Foss et al sample, meaning that participants had other health issues that had more effect on their falls risk than cataract. Interestingly, the findings were in contrast to our previous population-based study in Western Australia which reported an increase in falls after first and second eye cataract surgeries. ${ }^{8}$ This may be due to the previous study including only the most serious type of falls that resulted in hospitalization. As it was a linked database study, it was also impossible to control for visual measures and lifestyle factors that may have affected falls risk, and this may have resulted in the differences between studies.

It is also known that a small proportion of bilateral cataract patients experience very large differences in vision between the unoperated and operated eyes following first eye surgery, negatively affecting their vision..$^{23,24}$ This may explain the smaller overall benefit observed for the second eye compared with the first eye surgery as it is likely that these particular patients benefit significantly from second eye surgery in terms of falls prevention, whereas other patients may experience minimal or no additional benefit. This should be investigated further with a larger sample size.

It should be noted that improvements in visual function, especially contrast sensitivity were relatively small in our cohort following first and second eye cataract surgeries. This may be because they had better baseline vision, including contrast sensitivity than in previous studies examining the impact of cataract or cataract surgery on the number of falls. ${ }^{7,21}$ This indicates that cataract surgery has important benefits in terms of falls prevention, even when visual impairment from cataract is not severe, providing a case for expedited cataract surgery and shorter waiting lists. Also only a very small proportion of falls required medical treatment, and all of these required only a general practitioner visit. The absence of hospitalization of falls among our sample was unexpected with reference to previous data ${ }^{25}$ but might 
be due to the better baseline vision and younger age among this sample. However, nine of the participants experienced more than one fall during the study period suggesting that particular patients are at the risk of recurrent falls, despite undergoing cataract surgery.

This study also found that binocular visual acuity was significantly associated with risk of falls. This is positive since visual acuity is the measure most commonly used in clinical practice to determine the level of visual impairment and need for surgery. However, improved contrast sensitivity was also found to be significantly associated with a decreased risk of falls, and it is consistent with the findings of previous research. ${ }^{7,26,27}$ Further research should examine specific thresholds of contrast sensitivity impairment that affect falls risk so that this measure could be considered in clinical practice when assessing the patients' need for surgery and their risk of falls.

Interestingly, undertaking "sufficient" exercise was not significantly associated with falls among the sample. A 2012 systematic review stated that both group exercise programs and home-based exercise programs decreased the risk and rate of falls, whereas a 2015 meta-analysis found that there was no significant reduction in the number of falls for those who took part in an exercise program. ${ }^{28-30}$ It is possible that participating in physical activity with poor vision actually increases opportunities to fall, mitigating benefits.

Strengths of the study included data collection at three time points, the use of falls diaries and accounting for a large range of potential confounding factors. This study also had limitations. First, the sample size was small resulting in a small number of falls during each time period, and this may not have been adequate to detect all associations. The time period between first and second eye surgeries was also short for some participants, reducing the opportunity for falls to occur during this time. In addition, falls information was selfreported so may have been subject to recall bias. However, falls diaries returned monthly and follow-up calls would have minimized these inaccuracies. Prescription medications and comorbidities were self-reported, hence may be inaccurate. The impact of refractive management on falls risk was also not included as part of this analysis since participants undertook the visual tests while wearing their normal refraction used for daily living tasks.

\section{Conclusion}

This study found that first and second eye cataract surgeries reduced the risk of falls among a cohort of bilateral cataract patients with relatively good baseline vision. This suggests that timely first and second eye cataract surgeries could play an important role in reducing the burden of falls among older adults with cataract.

\section{Data sharing statement}

Data are not available for sharing due to confidentiality requirements.

\section{Acknowledgment}

The authors thank all participants who volunteered.

\section{Author contributions}

YRF was involved in analysis and interpretation of the data and preparation of the manuscript. LBM contributed to study concept and design, acquisition of data, analysis and interpretation of the data, and preparation of the manuscript. MLF contributed to study concept and design, interpretation of the data, and preparation of the manuscript. KJB was involved in analysis of the data and preparation of the manuscript. SA was involved in acquisition of data and preparation of the manuscript. All authors contributed toward data analysis, drafting and critically revising the paper, gave final approval of the version to be published, and agree to be accountable for all aspects of the work.

\section{Disclosure}

The authors report no conflicts of interest in this work.

\section{References}

1. Harwood RH. Visual problems and falls. Age Ageing. 2001;30(Suppl 4): $13-18$.

2. Australian Institute of Health and Welfare (AIHW). First Report on the National Health Priority Areas, Full Report, AIHW Cat. No. PHE 1. Canberra, Australia: Commonwealth Department of Health and Family Services; 1997.

3. Pascolini D, Mariotti SP. Global estimates of visual impairment: 2010. Br J Ophthalmol. 2012;96(5):614-618.

4. Gothwal VK, Wright TA, Lamoureux EL, Khadka J, McAlinden C, Pesudovs K. Improvements in visual ability with first-eye, second-eye, and bilateral cataract surgery measured with the visual symptoms and quality of life questionnaire. J Cataract Refract Surg. 2011;37(7): 1208-1216.

5. Desapriya E, Subzwari S, Scime-Beltrano G, Samayawardhena LA, Pike I. Vision improvement and reduction in falls after expedited cataract surgery: systematic review and metaanalysis. J Cataract Refract Surg. 2010;36(1):13-19.

6. Palagyi A, Morlet N, McCluskey P, et al. Visual and refractive associations with falls after first-eye cataract surgery. J Cataract Refract Surg. 2017;43(10):1313-1321.

7. To KG, Meuleners L, Bulsara M, et al. A longitudinal cohort study of the impact of first- and both-eye cataract surgery on falls and other injuries in Vietnam. Clin Interv Aging. 2014;9:743-751.

8. Meuleners LB, Fraser ML, Ng J, Morlet N. The impact of first- and second-eye cataract surgery on injurious falls that require hospitalisation: a whole-population study. Age Ageing. 2014;43(3):341-346.

9. Acosta-Rojas ER, Comas M, Sala M, Castells X. Association between visual impairment and patient-reported visual disability at different stages of cataract surgery. Ophthalmic Epidemiol. 2006;13(5):299-307. 
10. Lundstrom M, Stenevi U, Thorburn W. Quality of life after first- and second-eye cataract surgery: five-year data collected by the Swedish National Cataract Register. J Cataract Refract Surg. 2001;27(10): 1553-1559.

11. Shekhawat NS, Stock MV, Baze EF, et al. Impact of first eye versus second eye cataract surgery on visual function and quality of life. Ophthalmology. 2017;124(10):1496-1503.

12. To KG, Meuleners LB, Fraser ML, et al. The impact of cataract surgery on vision-related quality of life for bilateral cataract patients in Ho Chi Minh City, Vietnam: a prospective study. Health Qual Life Outcomes. 2014;12:16.

13. Coleman AL, Stone K, Ewing SK, et al. Higher risk of multiple falls among elderly women who lose visual acuity. Ophthalmology. 2004; 111(5):857-862.

14. Yip JL, Khawaja AP, Broadway D, et al. Visual acuity, self-reported vision and falls in the EPIC-Norfolk Eye study. Br J Ophthalmol. 2014; 98(3):377-382.

15. Palagyi A, McCluskey P, White A, et al. While we waited: incidence and predictors of falls in older adults with cataract. Invest Ophthalmol Vis Sci. 2016;57(14):6003-6010.

16. Folstein MF, Folstein SE, McHugh PR. "Mini-mental state". A practical method for grading the cognitive state of patients for the clinician. J Psychiatr Res. 1975;12(3):189-198.

17. Hauer K, Lamb SE, Jorstad EC, Todd C, Becker C. Systematic review of definitions and methods of measuring falls in randomised controlled fall prevention trials. Age Ageing. 2006;35(1):5-10.

18. Australian Institute of Health and Welfare (AIHW). The Active Australia Survey: A Guide and Manual for Implementation, Analysis and Reporting. Canberra, Australia: AIHW; 2003.

19. Ferris FL 3rd, Kassoff A, Bresnick GH, Bailey I. New visual acuity charts for clinical research. Am J Ophthalmol. 1982;94(1):91-96.

20. Zeger SL, Liang KY. Longitudinal data analysis for discrete and continuous outcomes. Biometrics. 1986;42(1):121-130.
21. Harwood RH, Foss AJ, Osborn F, Gregson RM, Zaman A, Masud T. Falls and health status in elderly women following first eye cataract surgery: a randomised controlled trial. Br J Ophthalmol. 2005;89(1): 53-59.

22. Foss AJ, Harwood RH, Osborn F, Gregson RM, Zaman A, Masud T. Falls and health status in elderly women following second eye cataract surgery: a randomised controlled trial. Age Ageing. 2006; 35(1):66-71.

23. Castells X, Comas M, Alonso J, et al. In a randomized controlled trial, cataract surgery in both eyes increased benefits compared to surgery in one eye only. J Clin Epidemiol. 2006;59(2):201-207.

24. Comas M, Castells X, Acosta ER, Tuni J. Impact of differences between eyes on binocular measures of vision in patients with cataracts. Eye. 2007;21(6):702-707.

25. Dhital A, Pey T, Stanford MR. Visual loss and falls: a review. Eye (Lond). 2010;24(9):1437-1446.

26. de Boer MR, Pluijm SM, Lips P, et al. Different aspects of visual impairment as risk factors for falls and fractures in older men and women. J Bone Miner Res. 2004;19(9):1539-1547.

27. Lord SR, Dayhew J. Visual risk factors for falls in older people. J Am Geriatr Soc. 2001;49(5):508-515.

28. Albert SM, King J. Effectiveness of statewide falls prevention efforts with and without group exercise. Prev Med. 2017;105:5-9.

29. Gillespie LD, Robertson MC, Gillespie WJ, et al. Interventions for preventing falls in older people living in the community. Cochrane Database Syst Rev. 2012;9:CD007146.

30. Gleeson M, Sherrington C, Keay L. Exercise and physical training improve physical function in older adults with visual impairments but their effect on falls is unclear: a systematic review. J Physiother. 2014; 60(3):130.E-135.E.
Clinical Interventions in Aging

\section{Publish your work in this journal}

Clinical Interventions in Aging is an international, peer-reviewed journal focusing on evidence-based reports on the value or lack thereof of treatments intended to prevent or delay the onset of maladaptive correlates of aging in human beings. This journal is indexed on PubMed Central, MedLine,

\section{Dovepress}

CAS, Scopus and the Elsevier Bibliographic databases. The manuscript management system is completely online and includes a very quick and fair peer-review system, which is all easy to use. Visit http://www.dovepress. com/testimonials.php to read real quotes from published authors. 